OPEN ACCESS

Edited by: Kelly Wrighton,

The Ohio State University, USA

Reviewed by:

Suzanne Lynn Ishaq, Montana State University, USA Zhongtang $Y u$,

The Ohio State University, USA

*Correspondence:

David R. Yáñez-Ruiz david.yanez@eez.csic.es

Specialty section This article was submitted to Systems Microbiology, a section of the journal Frontiers in Microbiology

Received: 24 July 2015 Accepted: 01 October 2015 Published: 14 October 2015

Citation:

Yáñez-Ruiz DR, Abecia L and Newbold CJ (2015) Manipulating rumen microbiome and fermentation through interventions during early life: a review. Front. Microbiol. 6:1133. doi: 10.3389/fmicb.2015.01133

\section{Manipulating rumen microbiome and fermentation through interventions during early life: a review}

\author{
David R. Yáñez-Ruiz ${ }^{*}$, Leticia Abecia ${ }^{1}$ and Charles J. Newbold ${ }^{2}$ \\ ${ }^{1}$ Estación Experimental del Zaidín - Consejo Superior de Investigaciones Científicas, Granada, Spain, ${ }^{2}$ Institute of Biological, \\ Environmental and Rural Sciences, Aberystwyth University, Aberystwyth, UK
}

The nutritional manipulations of the rumen microbiome to enhance productivity and health are rather limited by the resilience of the ecosystem once established in the mature rumen. Based on recent studies, it has been suggested that the microbial colonization that occurs soon after birth opens a possibility of manipulation with potential to produce lasting effects into adult life. This paper presents the stateof-the-art in relation to early life nutritional interventions by addressing three areas: the development of the rumen as an organ in regards to the nutrition of the newborn, the main factors that determine the microbial population that first colonizes and establishes in the rumen, and the key immunity players that contribute to shaping the commensal microbiota in the early stage of life to understand host-microbiome specificity. The development of the rumen epithelium and muscularization are differently affected by the nature of the diet and special care should be taken with regards to transition from liquid (milk) to solid feed. The rumen is quickly colonized by all type of microorganisms straight after birth and the colonization pattern may be influenced by several factors such as presence/absence of adult animals, the first solid diet provided, and the inclusion of compounds that prevent/facilitate the establishment of some microorganisms or the direct inoculation of specific strains. The results presented show how early life events may be related to the microbial community structure and/or the rumen activity in the animals post-weaning. This would create differences in adaptive capacity due to different early life experiences and leads to the idea of microbial programming. However, many elements need to be further studied such as: the most sensitive window of time for interventions, the best means to test long term effectiveness, the role of key microbial groups and host-immune regulations.

Keywords: early life, microbial colonization, rumen development, rumen microbiome, weaning

\section{INTRODUCTION}

The forestomachs of ruminant animals contain a great diversity of prokaryotic (bacteria, archaea, virus) and eukaryotic (protozoa and fungi) micro-organisms that together breakdown and ferment the feed ingested by the host animal (Dehority, 2003). In the last decades there have been significant efforts to develop compounds that may shift the rumen fermentation toward more 
efficient metabolic pathways by targeting key groups of microorganisms (i.e., archaea in case of methanogenesis, Hart et al., 2008). However, the utility of such compounds often appears limited as results are often inconsistent or short-lived. This is mainly due to the difficulty in modifying a wellestablished and fully matured microbial ecosystem in the rumen of adult animals. There is ample evidence of a strong hostmicrobiota specificity (Kittelmann et al., 2014), implying that after any alteration (i.e., rumen digesta swapping, exogenous bacteria application or antibiotic treatment), once ceased, the microbial community composition and fermentation profile will return to the original pre-treatment composition (Weimer et al., 2010). The developing rumen in the new-born provides a unique opportunity for potential manipulation of such a complex microbial ecosystem.

Early experience ingesting feeds increases preference for and later consumption of those feeds by animals (Provenza and Balph, 1990). Early dietary experiences have a greater and more lasting effect than those occurring later in life (Distel et al., 1994). Different processes (neurological, morphological, and physiological) may be involved during early in life and can be altered so that animals can better manage in the environment in which they are reared from birth.

$\mathrm{Li}$ et al. (2012), based on 454-pyrosequencing of $16 \mathrm{~S}$ rDNA, reported that a total of 170 bacterial genera exists in the developing rumen of 14 days old calves, and that the microbiota was responsive to dietary modifications as well as physiological changes in the host. Earlier work reported that forage or concentrate diets fed around weaning had an impact on the bacterial population that established in the rumen (Eadie et al., 1959); however, the impact that this differentiation might have later in life on the rumen microbial ecosystem remained to be determined. Recent studies (YáñezRuiz et al., 2010; Abecia et al., 2013, 2014a) suggested that it would indeed be possible to promote different microbial populations establishing in the rumen of the young animal by manipulating the feeding management early in life that persisted in later life. This would create differences in adaptive capacity due to different early life experiences, leading to the idea of microbial programming. However, despite significant research effort, there is still a lack of understanding of the mechanisms governing microbial/host cell interactions, the development of the rumen and its microbial community, and the implications for the host when microbial colonization patterns are altered, especially the long-term effects. This paper will critically review the information published on: (i) the development of the rumen as an organ in regards to the nutrition of the newborn, (ii) the factors (maternal, dietary, etc.) that determine the microbial population that first colonizes and establishes in the rumen and (iii) the key immunity players that contribute to shaping the commensal microbiota in the early stage of life to understand host-microbiome specificity. The aim of the review is to evaluate the importance of the multiple factors in shaping the rumen microbiome and the potential of early life rumen microbial programming based on current research and to identify gaps of knowledge for future research studies.

\section{THE DEVELOPMENT OF THE RUMEN AS AN ORGAN AND THE INFLUENCE OF THE DIET}

Young ruminants present at birth an undeveloped reticulorumen, therefore, until the system is fully matured they function as monogastrics fed on milk-based diets that are not digested in the rumen but in the abomasum (Church, 1988; Davis and Drackley, 1998). As stated by Heinrichs (2005) 'a smooth transition from a monogastric to ruminant animal, with minimal loss in growth, requires the development of the reticulo-rumen and its associated microbial population for efficient utilization of dry and forage-based diets'.

Development of the rumen is an important physiological challenge for young ruminants (Jiao et al., 2015). It entails growth and cellular differentiation of the rumen, and results in a major shift in the pattern of nutrients being delivered to the intestines and liver, and thus the peripheral tissues of the animal (Baldwin et al., 2004). The development of the rumen involves three distinct processes: (i) anatomical development (growth in rumen mass and growth of rumen papillae; Reynolds et al., 2004), (ii) functional achievement (fermentation capacity and enzyme activity; Rey et al., 2012; Faubladier et al., 2013), and (iii) microbial colonization (bacteria, fungi, methanogens, and protozoa; Fonty et al., 1987; Fouts et al., 2012). This section addresses the first process, while microbial colonization will be discussed in Section "Factors that Influence the Microbiota Establishing in the Rumen and Long Term Effects."

An inadequate development of the rumen will affect nutrient digestion and absorption (Baldwin et al., 2004). On the other hand, a complete development of the rumen facilitates digestion of feed components, which provides nutrients for the physiological requirements of the animal. The anatomical development of the rumen is a process that occurs following three phases: non-rumination (0-3 weeks); transitional phase (3-8 weeks), and rumination (from 8 weeks on; Wardrop and Coombe, 1960; Lane et al., 2002).

During the transition from a pre-ruminant to a ruminant animal, growth and development of the ruminal absorptive surface area (papillae) is essential to enable absorption and utilization of digestion end products, specifically rumen volatile fatty acids (Warner et al., 1956). The presence and absorption of volatile fatty acids stimulates rumen epithelial metabolism and may be key in initiating rumen epithelial development (Baldwin and McLeod, 2000). Different studies (Nocek et al., 1984; Greenwood et al., 1997) have shown that ingestion of dry feeds and the resultant microbial end products stimulate the development of the rumen epithelium. However, different volatile fatty acids stimulate such development differently, as butyrate is most stimulatory, followed by propionate. With decreasing rumen $\mathrm{pH}$ and increasing butyrate concentrations, butyrate metabolism by the epithelium increases concomitantly (Baldwin and McLeod, 2000). A continuous exposure to volatile fatty acids maintains rumen papillae growth, size, and function (Warner et al., 1956). Thus, it is expected that diets consisting of milk, concentrates, or forages affect the rumen epithelial growth to different extents (Table 1). Moreover, 
TABLE 1 | Effect of different dietary interventions in early life on rumen development parameters.

\begin{tabular}{|c|c|c|c|c|c|}
\hline Dietary treatment & Rumen weight, kg & Wall thickness, cm & Papillae, $\mathbf{n} / \mathrm{cm}^{2}$ & pH & Study \\
\hline Corn processing & ND & Affected (1.06-1.21) & ND & Affected (5.41-5.66) & Lesmeister and Heinrichs, 2004 \\
\hline Supplemental yeast & ND & No effect & ND & ND & Lesmeister et al., 2004 \\
\hline Supplemental molasses & ND & No effect & ND & ND & Lesmeister and Heinrichs, 2005 \\
\hline Carbohydrate composition & Increased (0.73-1.73) & Increased (0.86-1.32) & & Affected (4.9-5.3) & Suárez et al., 2006 \\
\hline Milk allowance & Increased (1.37-1.89) & Increased (1.15-1.47) & Increased (71-86) & Decreased (6.22-5.66) & Khan et al., 2007 \\
\hline Milk allowance & Affected (0.58-1.35) & ND & ND & Affected (5.56-6.29) & Kristensen et al., 2007 \\
\hline Forage to concentrate ratio & Affected (0.95-1.45) & Affected (0.82-1.20) & ND & Affected (5.09-5.23) & Suárez et al., 2007 \\
\hline Starch sources & Affected (1.21-1.53) & Affected (1.55-1.95) & Affected (70-91) & Affected (5.46-5.79) & Khan et al., 2008 \\
\hline Provision of hay & Increased (1.59-1.89) & No effect & No effect & Increased (5.06-5.49) & Khan et al., 2011 \\
\hline Whole milk vs. milk replacer & No effect & ND & ND & No effect & Górka et al., 2011 \\
\hline Whole milk vs. milk replacer & Decreased (0.73-0.66) & ND & ND & Increased (6.12-6.57) & Abecia et al., 2014b \\
\hline Milk replacer feeding strategy & No effect & ND & ND & Affected (6.2-6.9) & Silper et al., 2014 \\
\hline
\end{tabular}

ND, not determined.

the establishment and activity of the rumen epithelial tissueassociated microbes (defined as epimural community) may be another factor that influences the extent of development of the rumen epithelium (Malmuthuge et al., 2012, see "Factors that Influence the Microbiota Establishing in the Rumen and Long Term Effects").

The chemical composition of the liquid (milk) feed and the effect of the oesophageal groove limit the process of physical and functional development of the rumen (Warner et al., 1956). In young ruminants fed only milk or milk replacer, the rumen development has been shown to be limited even up to 12 weeks of age (Tamate et al., 1962). Indeed, it has been reported a regression of rumen development when calves were changed from a solid diet and milk replacer to a solely milk/milk replacer diet (Harrison et al., 1960). Also, young ruminants receiving only milk/milk replacer had limited metabolic activity in the rumen epithelium and minimal absorption of volatile fatty acids (Heinrichs, 2005). Therefore, although milk based diet promote rapid and efficient growth of the young animal, it does not contribute to prepare the pre-ruminant to utilize solid diets.

Unlike liquid feeds, solid feeds are mainly directed to the reticulo-rumen for digestion (Church, 1988). Solid feed intake stimulates rumen microbial proliferation and production of volatile fatty acids, which have been shown to initiate rumen epithelial development, although, different solid feeds may differ in their ability to stimulate the development of the rumen. Both the chemical composition of feeds and the resultant microbial digestion end products have the greatest influence on the development of the rumen epithelium (Nocek et al., 1984).

Providing natural milk or milk replacer to newborn ruminants differs not only in their intrinsic differences in nutrient composition but also in the presence or absence of the dam. In ruminant farming two main systems for managing the young animals can be identified. In commercial dairy systems, calves are typically separated from the dam at a young age and fed either milk replacer or whole milk; on the contrary, in fattening systems, the newborns remain with the mother until weaning.
It has been recently reported that kid goats reared with the dam had greater rumen development than their twins that were fed on milk replacer and isolated from adult animals, despite both groups having access to the same forage and concentrate offered ad libitum (Abecia et al., 2014b). This is accordance with De Paula Vieira et al. (2012), which showed that calves reared in the presence of older companions exhibited more frequent and longer visits to the feeder, which they hypothesized to be a consequence of social learning (Galef and Giraldeau, 2001). However, the advantage of the direct microbial inoculation through physical contact with the dam deserves further attention, as discussed in the following section.

In intensive farming, the supplementation with concentrates is the most common method of providing nutrients to the animal with emphasis on offering young ruminants concentrate solid starter at a relative early age (Jiao et al., 2015). Therefore, in the last years, research on rumen development has been mainly directed on this type of feeding system and the main factors that affect rumen development in ruminants fed a range of different diets (Owens et al., 1993), with the primary attention on diet composition (Table 1, Coverdale et al., 2004; Suárez et al., 2007; Khan et al., 2011). Feeding concentrate feeds in early life stimulates the development of the epithelium, while forages with large particle size or high fiber sources appear to be the primary stimulators of rumen muscularization and volume (Zitnan et al., 1998). Several recent studies have shown that another effective method to foster solid feed intake in calves, contrary to what it has been traditionally adviced, is to provide ad libitum access to poor quality (nutritionally) chopped straw or hay (Jiao et al., 2015). Castells et al. (2013) conducted a metaanalysis and concluded that there were no differences in gut fill between calves consuming no forage and calves consuming forage up to $5 \%$ of total solid feed consumption. Thus, it can be concluded that when forage consumption is less than $5 \%$ of the total solid feed intake, gut fill is negligible and thus advantages reported in performance and efficiency when feeding chopped forages to calves are not an artifact due to gut fill. Depriving calves from forage during the pre-weaning phase may offer yet another physiological and dietary adaptation challenge to young 
calves during the transition when presented with forage for the first time. Phillips (2004) reported that calves fed fresh grass during the milk-feeding period spent more time eating on a pasture compared with those that received no forage before weaning. Recent data also shows that $22 \%$ of the variation in milk yield in first lactation is associated to the average daily gain during the first weeks of life (Soberon et al., 2012). However, the long-term effects of early life nutritional management in relation to rumen development are still largely unknown and there are factors that still need to be carefully considered such as composition of the starter, type of forage and timing of its introduction.

When addressing the development of the rumen, the following question arises: does the development of the organ determine which microbes colonize the rumen or do the microbes themselves shape the rumen development through their activity and specific signaling? In the adult animal, the diet is the main driver of the microbial community structure (McCann et al., 2014), but in the pre-ruminant both microbial colonization and rumen development may interact in a way that one influences the other. Also, it is still unknown to what extent the animal is genetically pre-determined to develop a certain type of rumen (i.e., epithelium, muscularization, contractions). Goopy et al. (2012) reported that low methane yield sheep were associated with a shorter mean retention time of particulate and liquid digesta, lesser amounts of rumen particulate content and a smaller rumen volume. Low methane yield sheep harbor a distinctive bacterial community structure (Kittelmann et al., 2014). Thus, it could be hypothesized that promoting a large rumen by feeding more forage in early life may determine the type of microbiota harbored in the rumen and consequently the digestion efficiency of the animal.

\section{FACTORS THAT INFLUENCE THE MICROBIOTA ESTABLISHING IN THE RUMEN AND LONG TERM EFFECTS}

\section{Sequential Microbial Colonization of the Rumen}

The gastrointestinal tract of most animals is supposed to be sterile and germ free right after birth; then, microbes from other adult animals and the surrounding environment subsequently colonize the rumen until a very complex and diverse microbial population develops (Ziolecki and Briggs, 1961). Several studies have shown that in young ruminants and during rumen development, ingested microbes colonize and establish in a defined and progressive sequence (Stewart et al., 1988). Ample evidence (Fonty et al., 1987; Morvan et al., 1994) now exists that a significant proportion of the strict anaerobes that become predominant in the mature rumen are already present in the rumen 1 or 2 days after birth. The use of molecular techniques has shown the complex microbial community that soon establishes in the non-mature rumen. All major types of rumen bacteria, including proteolytic and cellulolytic species, as well as some niche specialists, are present in the rumen microbial community of 14 days old calves (Li et al., 2012), whilst Jami et al. (2013) stated that "some rumen bacteria essential for mature rumen function could be detected as early as 1 day after birth". Rey et al. (2013) monitored the establishment of ruminal bacterial community in dairy calves from birth to weaning. They showed that the establishment is rapid after birth and sequential: Proteobacteria is gradually replaced by Bacteroidetes as the main Phyla. Between days 3 and 12, the bacterial community was composed of many bacteria present in the developed rumen, showing that the bacteria responsible for the degradation of feeds are present before the ingestion of solid substrate begins. Between days 9 and 15, diet influence seemed strongest and was associated with a change in the bacterial community structure. From 15 days on, the community no longer exhibited clear time related changes at phyla level although variations on the relative abundance of some genera did occur (Table 2).

Becker and Hsiung (1929) first demonstrated that the rumen ciliate protozoa are passed from animal to animal by direct transfer of saliva containing the active organisms as there is no resistant phase or cysts in their life cycle (Strelkov et al., 1933). Ciliate protozoa can normally be seen in the rumen of young ruminants within 2 weeks of birth with small entodinia established before large endomorphs and holotrich protozoa (Eadie, 1962). However, if animals are isolated from other ruminants shortly after birth no protozoa establish (Bryant and Small, 1960; Eadie, 1962), a property that has been widely used and continues to be used to study the role of protozoa in the rumen (Belanche et al., 2014).

Methanogenic archaea have been found in the undeveloped rumen of lambs well before the arrival of solid substrate to the rumen (2-4 days) and reach concentrations equivalent to those in adult animals around 10-14 days after birth (Fonty et al., 1987; Morvan et al., 1994). The development of molecular techniques allowed the detection of methanogenic archaea at earlier stages as probably they could not be detected by classical microbial counting (Gagen et al., 2012). Guzman et al. (2015) has

TABLE 2 | Age classification of bacterial groups colonizing the rumen from birth to weaning. Values expressed as range of mean percentages ${ }^{a}$.

\begin{tabular}{lccccc}
\hline & \multicolumn{5}{c}{ Age (days) } \\
\cline { 2 - 6 } & $\mathbf{3}$ & $\mathbf{7}$ & $\mathbf{1 4}$ & $\mathbf{2 8}$ & $\mathbf{4 2}$ \\
\hline Phyla & & & & & \\
\hline Proteobacteria & $46.6-70.4$ & $16.9-18.7$ & $6.45-16.9$ & $1.8-27.6$ & $12-27.6$ \\
Bacteroidetes & $13.9-42.6$ & $56.3-56.9$ & $46-61.3$ & $49.9-56.3$ & $56.3-74$ \\
Firmicutes & $5.05-13.9$ & $13.9-17.5$ & $13.9-34$ & $13.9-42.1$ & $10-13.9$ \\
Actinobacteria & $0.05-4.9$ & $0.55-4.9$ & $0.95-4.9$ & $0.25-4.9$ & 4.9 \\
Fusobacteria & $4.7-5.55$ & $4.7-5.30$ & $0.2-0.55$ & $0.2-0.3$ & $0.2-0.4$ \\
Spirochaetes & $0-0.4$ & $0.1-0.4$ & $0.4-2.60$ & $0.4-0.85$ & 0.4 \\
Fibrobacteres & $0-0.3$ & $0-0.3$ & $0.2-0.3$ & $0.3-1.45$ & $0.3-1.6$ \\
Tenericutes & 0 & 0.80 & 0.20 & 0.90 & 0.95 \\
Elusimicrobia & 0 & 0 & 0.20 & 1.45 & 2.1 \\
Lentisphaerae & 0 & 0 & 0.15 & 0.20 & 0.31 \\
\hline
\end{tabular}

a Data collected from Li et al. (2012), Jami et al. (2013) and Rey et al. (2013). 
recently reported that at day 0 of life $M$. mobile, $M$. votae, and Methanobrevibacter sp. were detected in the rumen of neonatal dairy calves.

As reviewed by Stewart et al. (1988), anaerobic fungi established in the rumen of flock-reared lambs by 8-10 days after birth (Fonty et al., 1987). They were found in all lambs by 3 weeks of age and interestingly then were no longer detectable in 9 of the 11 lambs studied when a diet based on concentrate was provided. The fungal population was mainly composed of Neocallimastix frontalis; Sphaeromonas communis was found only sporadically. The early appearance of these fungi is another characteristic of the rumen. These microorganisms which had only previously been found in mature ruminants or when forage-rich diets are fed (Orpin and Joblin, 1988) are apparently able to develop in the rumen before solid substrate enters the rumen.

In addition to the colonization pattern of the different microbial groups in the rumen, special attention should be paid to the microbial community associated to the rumen wall. Stewart et al. (1988) stated that the epimural bacterial community is established shortly after birth and soon reaches concentration equivalent to those in the adult while the diversity of this community seem to change with age (Mueller et al., 1984a; Rieu et al., 1990). Mueller et al. (1984a) described 24 morphological types of bacteria associated to the rumen wall in 1 - to 10 -week old lambs by using scanning electron microscopy, although only seven types, found in both the lamb and the adult, could be considered indigenous members of the epimural community. This community follows a characteristic succession, with significant changes occurring in the generic composition through the first 10 weeks of life. According to Mueller et al. (1984b), the epimural community does not appear to be markedly different taxonomically from the bacterial community of rumen contents, since most isolated strains could be placed into common rumen genera. However, recent studies conducted using molecular tools disagree with that statement. Sadet et al. (2007) using PCR-DGGE found that the epithelial community differed from that of rumen contents. As expected, the nature of the feed influenced the bacterial communities from the solid and liquid rumen phases but no diet effect was observed in the rumen epithelial profiles, suggesting a strong host effect on this bacterial population. More recently, Malmuthuge et al. (2014) reported large differences between digesta and epimural bacterial communities in the rumen of pre-weaned calves, highlighting greater abundances of Prevotella and lower abundances of Bacteroidetes in digesta compared with epimural bacterial communities. Moreover, the apparent association between the development of the mucosal bacteria community with the expression of some key immune related genes in mucosal tissue (Malmuthuge et al., 2012), suggests that future work on rumen colonization should include the study of the epimural community.

\section{Factors that Influence Early Life Colonization}

Given that the different trophic niches in the rumen ecosystem are first occupied during early life and that a key turning point in microbial colonization is the introduction of solid feed in the diet (Rey et al., 2013), an important issue to address is whether management of the newborn alters the colonization pattern. As described in Section "Sequential Microbial Colonization of the Rumen," there is now ample evidence of the early colonization of the rumen by anaerobic microorganisms, however, very few studies have actually compared the colonization pattern of the undeveloped rumen in the context of the factors that facilitate (or prevent) the colonization of some microbial groups (i.e., maternal influence, offspring reared in isolation, liquid/solid feed, use of additives, etc).

Protozoa are not essential for the normal rumen functioning (Williams and Coleman, 1992); however, the presence/absence of protozoa has been associated with the structure of different bacterial and methanogens communities and different rumen fermentation pattern (Yáñez-Ruiz et al., 2007; Belanche et al., 2014). Adult ruminants harbor distinctive protozoal populations with key species such as Polyplastron and Epidinium indicative of types A and B populations, respectively (Williams and Coleman, 1992). The introduction of Polyplastron into the rumen of animals harboring a type $B$ protozoal population leads to the elimination of type B protozoa, however, within most flocks sheep exist with approximately the same number of animals harboring a type A and type B populations, clearly some unknown host factor influences the colonization of the rumen of individual sheep by protozoa (Williams and Coleman, 1992). Skillman et al. (2004) used twin lambs to identify methanogens colonizing the rumen of young lambs. The similarities between the rumen methanogen populations found in twins suggested that the dam was the main source of methanogen inoculation. The maternal influence has been further supported in recent studies in terms of microbial development in pre-ruminants subjected to anti-methanogenic treatments (bromochloromethane, BCM). Abecia et al. (2013, 2014a) reported that the archaeal community establishing in the rumen of kids depended on whether the doe was treated or not with BCM. This suggests that any intervention applied in the early life of young animals raised by the dams should consider applying the same treatment to the doe.

Both Abecia et al. (2014b) and Belanche et al. (2015) showed a different colonization pattern for protozoa in artificially reared animals as compared to those raised by the dams. Abecia et al. (2014b) showed that natural milk feeding via the dam vs. artificial feeding with milk replacer resulted in consistently lower $\mathrm{pH}$ in the developing rumen of goat kids that stayed with the mothers. They hypothesized that naturally raised kids would have consumed more concentrate at an earlier stage as a result of social feeding learning. An environment with a different $\mathrm{pH}$ during the development would be more beneficial for some microbial groups (Palmonari et al., 2010) and may set a different microbial population in the adult animal.

Anderson et al. (1987) showed that introducing solid feed for early weaning ( 3 weeks) in calves promoted greater microbial abundance in the rumen as compared to calves weaned conventionally ( 6 weeks), but no assessment of the composition of the microbiota was performed. Early studies (Eadie et al., 1959; Ziolecki and Briggs, 1961) reported that giving forage or forage and concentrate around weaning determined the concentration 
of some anaerobic bacteria (lactobacilli and lactate-utilizing cocci), although no information on the persistency of such effect was provided. Yáñez-Ruiz et al. (2010) reported that feeding forage vs. concentrate around weaning modified the bacterial population colonizing the rumen of lambs and that the effect persisted over 4 months, suggesting the possibility of further exploring the feasibility of manipulating the microbial populations present in the adult animal using diets or dietary additives fed early in life.

In addition to the introduction of solid diet around weaning, nutritional interventions in early life may include (i) the direct inoculation of specific microorganisms or (ii) the use of compounds (i.e., additives) that prevent or facilitate the colonization of some microbial groups. Feeding live microorganisms to ruminants is not a novel concept and extensive work has been published on the use of 'direct-fed microbials' (DFM; Martin and Nisbet, 1992; Jeyanathan et al., 2014). Theodorou et al. (1990) reported that the addition of the anaerobic rumen fungus Neocallimastix sp increased intake and liveweight gain in calves at weaning, whilst Ziolecka et al. $(1984 a, b)$ reported that a stabilized rumen extract enhanced live weight gain and stimulated rumen development in calves during weaning and Zhong et al. (2014) demonstrated that inoculation of fresh rumen fluid into the rumen of lambs for 7 days improved average daily gain and digestibility in early weaned lambs. Nakanishi et al. (1993) found that adding lactic acid bacteria to starter diets of Holstein calves stimulated rumination and ruminal development, however, no performance benefits were observed and possible microbial changes during rumen development were not determined. Lesmeister et al. (2004) evaluated the effect of supplementing yeast (Saccharomyces cerevisiae) culture on rumen development and growth performance in neonatal dairy calves. Although yeast cultures are widely used in ruminant nutrition, the concept of applying them in the diet of pre-ruminants deserves further assessment. They conclude that the addition of yeast in dairy calf starter at $2 \%$ enhanced dry matter intake and growth and slightly improved rumen development. Unfortunately they did not study either the effect on the rumen microbiota or the longterm effects in the animals. Other microbes targeting the rumen (i.e., Megasphaera elsdenii, propionibacteria) have been used as rumen probiotics but to our knowledge only in adult animals (Klieve et al., 2003).

A different experimental approach is to provide specific microbes in gnotobotically reared neonates. Gnotobitic lambs harboring either a simple or complex microbiota are an important method for investigating the role of specific microbes in the rumen. This approach has been used mainly to gain insight in the manipulation of microbes directly involved in $\mathrm{H}_{2}$ transfer within the rumen. Hydrogenotrophic acetogens colonize first the rumen and then they are gradually replaced by methanogenic archaea as the rumen develops (Gagen et al., 2012). The early establishment of acetogenic and sulfate-reducing bacteria underlines the competition that exists between $\mathrm{H}_{2}$-utilizing species. Naturally reductive acetogenesis is not a significant hydrogen sink in the rumen. However, in the absence of methanogenesis, acetogens contribute to
$\mathrm{H}_{2}$ capture and can sustain functional rumen. Fonty et al. (2007) demonstrated using gnotobiotic lambs, that in animals lacking ruminal methanogens, the introduction of acetogens made reductive acetogenesis the major hydrogenotrophic process and that the effects of such intervention applied after birth persisted 12 months later. They suggested that if reliable methods for eliminating methanogens from early life and maintained the inoculation with acetogens could be a feasible option to decrease methane emissions from adult animals. More recently, Gagen et al. (2012) used lambs that were born naturally, left with their dams for $17 \mathrm{~h}$ and then placed into a sterile isolator and reared aseptically. They were inoculated with cellulolytic bacteria and later with Methanobrevibacter sp.7 to investigate the effect of methanogen establishment on the rumen acetogen population since they lacked cultivable methanogens. Methanogens were present in lambs isolated $17 \mathrm{~h}$ after birth, though were undetectable using traditional cultivation techniques. Methanogen numbers were low in these lambs $\left(<10^{4}\right.$ rrs copies per microgram of DNA) however, mcrA diversity was not dissimilar to that found in 2-year-old conventional sheep. This suggests that early colonizing methanogens may persist in the rumen and supports the potential of early life microbial programming.

With regards to the suppression of methanogens in early life, the use of compounds that inhibit the establishment of certain microbial groups or favor the development of others is now starting to attract attention. Abecia et al. (2013, 2014a) showed that application of BCM to young goat kids modified archaeal colonization of the rumen, which was linked to a reduction in methane emission of around $50 \%$, with the effects persisting for 3 months after weaning and cessation of treatment in kids raised by does that received the same treatment as the kids.

\section{Timing for Interventions in Early Life and Persistency of the Effects}

Given that particular factors favor the establishment of certain microorganisms, we still need to know what the most sensitive window of time for interventions is in early life. Recent work (Rey et al., 2013; Abecia et al., 2014b; Guzman et al., 2015) showed that initial colonization occurs straight after birth and that it takes 3-4 weeks for the bacterial community structure to reach a certain degree of stabilization from birth, suggesting that this period is critical. However, this assumes that once the community is more or less constant, there is no room for 'programming' and this has not yet been fully confirmed. It is clear that nutrient supply and hormonal signals at specific times during development (both pre- and early post-natal) exert permanent changes in the metabolism of humans (Fall, 2011), as well as changes in performance, body composition, and metabolic function of the offspring of livestock (Wu et al., 2006). These changes occur through processes generically referred to as fetal programming and metabolic imprinting. The information available in ruminants suggests that microbial colonization occurs earlier than functional achievement (i.e., a functioning rumen), with anatomic development occurring last (Jiao et al., 2015). However, the actual window of time in which such changes 
can be exerted in relation to microbial colonization and more importantly the persistency of the imprint needs to be further clarified. Therefore, there is urgent need to further address this question with more fundamental research. Rey et al. (2013) showed substantial colonization by the main bacterial groups in the first days of life. Likewise, Guzman et al. (2015) reported the presence of methanogenic archaea and fibrolytic rumen bacteria at day 0 in neonatal dairy calves, which suggests that the window for intervention starts straight after birth. Along these lines, there are some reported cases of human twins that harbor different gut microbiota (Clemente et al., 2012), which also offers promise for the potential of early life programming interventions. Studies in humans showed that early gut colonizers, such as those acquired from parents, can exert physiological, metabolic, and immunological effects for most of our lives (Faith et al., 2013).

\section{HOST IMMUNE RESPONSE TO MICROBIOTA}

The gastrointestinal tract has a diverse array of non-specific and specific protective mechanisms to allow it to coexist with resident microbiota (Hooper et al., 2012). The functions of nutrients absorption, symbiotic microbial tolerance and pathogenic microbial barrier, create a conflict in function requiring a complex system of physical, biochemical, and cellular mechanisms for protection of the intestinal mucosa against invading pathogens (Kuhn and Stappenbeck, 2012).

The training or education process that the immune system needs to go through to learn how to deal with microbial loads has been widely highlighted ( $\mathrm{Wu}$ and $\mathrm{Wu}, 2012)$ and this is of particular importance during early life stages (Collado et al., 2012); however, the mechanisms involved in the 'tolerance' to the first colonizers of the rumen are largely unknown. The physiological elements involved in the case of the rumen may differ from other parts of the gastrointestinal tract due to the nature of the fermentation and the constant exposure of the rumen wall to microbial biomass. The forestomachs of the ruminant species are expanded esophageal portions lined by stratified squamous epithelium. As stated by Trevisi et al. (2014), scant information is available about the organization of the epithelial immune system in forestomachs as opposed to the impressive amount of data about the intestinal tract of both ruminant and non-ruminant species (Dommett et al., 2005). In general, the immune response in the mucosal areas of the gut is orchestrated by mucosal-associated lymphoid tissue (MALT) and gut-associated lymphoid tissue (GALT) in the gut. However, in the rumen no organized lymphoid tissue exists in the epithelium (Sharpe et al., 1977). The rumen epithelium includes up to a 15 cell layer, which can limit the permeability of large molecules. Therefore, the microbial equilibrium in the rumen is achieved by a combination of different mechanisms, illustrated in Figure 1: (i) constant supply of Immunoglobulins (IgA and IgG) via saliva (Williams et al., 2009), (ii) the activity of Toll-like receptors (TLRs, Malmuthuge et al., 2012), (iii) a group of genetically encoded pattern recognition receptors
(Seabury et al., 2010); (iv) peptidoglycan recognition proteins (PGLYRP1, Malmuthuge et al., 2012), and (v) antimicrobial peptides defensins (Malmuthuge et al., 2012; Meade et al., 2014).

Blood serum in animals contains circulating antibodies to a wide range of Gram-negative bacteria, particularly enterobacteria (Landy and Weidanz, 1964). The antibodies are considered to be natural antibodies produced in the absence of overt infection (Boyden, 1966). Sharpe et al. (1969) found antibodies against specific strains of rumen bacteria in the blood of cows, sheep, goats, and horses, but not in pigs, rabbits, and humans. They showed the high specificity of the natural agglutinating antibodies in ruminants in absorption tests, which was further confirmed by the absence of agglutinins against a human Escherichia coli strain although they were detected against a rumen E. coli strain. A close relationship seems to exist between motility of the rumen microorganisms and their ability to stimulate natural antibodies, with antibodies being detected against motile Butyrivibrio, Streptococci, and Lactobacilli (Sharpe et al., 1969). Further work showed that antibodies against these organisms were present in bovine colostrum at the same level as serum and were transferred to the calf serum via colostrum (Sharpe et al., 1977). While not excluding the possibility that non-viable rumen bacteria leaving the abomasum could be a source of antigenic stimulus in the small intestine, an early study (Latham et al., 1971) investigated the caecum as an alternative site of antigenic stimulus. Many of the bacteria in the caecum are similar to those in the rumen, however, whereas the epithelium of the rumen is non-glandular and keratinized that of the caecum contains lymphatic tissue and plasma cells. The role of the caecum as active immune organ needs to be further studied.

Sharpe et al. (1977) used four gnotobiotic lambs, reared on milk, a starter ration and then grass cubes to understand the relationship between rumen microbial colonization in early life and antigen production. The lambs were inoculated with strains of Veillonela, Prevotella ruminicola, Ruminicoccus, Selenomonas, Megasphaera, Lactobacillus, Butyrivibrio and, in one case, E. coli. Prevotella, Selenomonas, and Megasphaera gave a strong immunological response, with antibodies to the former bacteria appearing at 20-40 days after inoculation and to the Megasphaera at 28-74 days. Agglutinins to Veillonella and Ruminococcus were weak and appeared only at 100-136 days after inoculation. As expected, no agglutinins were detected against non-inoculated bacteria. The gnotobiotic lambs did not receive colostrum and were born with only traces of immunoglobulins, but after 74-77 days had synthesized appreciable amounts of IgM and relatively little IgG. Since the primary antigenic response of an animal is to produce IgM, the preponderance of IgM is not surprising. At 140 days, IgG levels had risen considerably to similar levels as IgM. These results highlighted the strong link between rumen microbial colonization and specific antigen production. Unfortunately, no further work has been conducted in animals reared under different conditions in early life.

As noted earlier, saliva seems to be the main vehicle of introducing immunoglobulins in to the rumen. The levels of IgA and IgG in cattle serum, saliva, and rumen fluid have been studied recently in the context of exploring the possibility of vaccinating ruminants against specific rumen microorganisms (Subharat 

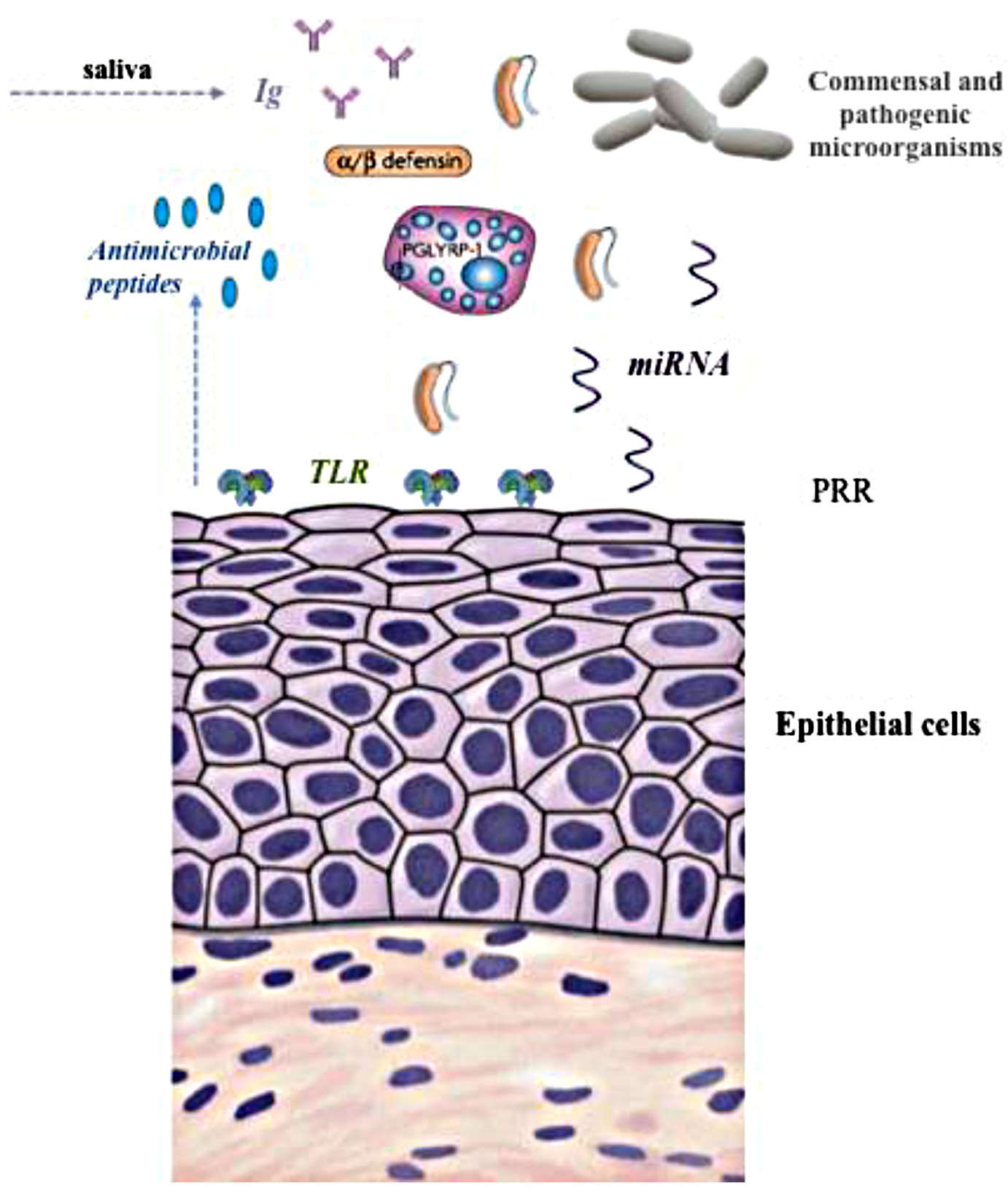

\section{PRR}

\section{Epithelial cells}

FIGURE 1 | Illustration of different elements of the immune-regulation of the rumen microbiome. TLR, Toll-like receptor; PRR, pattern recognition receptors

et al., 2015). These studies have confirmed that the major class of immunoglobulin in bovine saliva is $\operatorname{IgA}$ and showed that this class of immunoglobulin is also the dominant type in the rumen. In contrast, in serum the major class is IgG. IgA is apparently more resistant to degradation in the rumen compared to IgG, possibly because the secretory component of IgA makes the immunoglobulin more resistant to protease activity in the rumen (Snoeck et al., 2006). Although the research conducted in developing vaccines against specific rumen microorganisms proves that an increase in the titres of Ig in saliva can be achieved, the role of the constant supply of Ig into rumen through saliva in shaping the commensal microbial community and how this innate response functions during rumen development are as yet unknown.

A change in the diet of the animal can result in a shift in the proportion of microbial groups in the rumen (Petri et al., 2013) but little is known as to how the immune system deals with such a shift in ruminants. Some research has been conducted in this area in animals subjected to rumen acidosis challenge. Chen et al. (2012) reported a significant variation of TLR4 gene expression in the rumen epithelium of the animals with different susceptibility to acidosis. The observed correlations between copy number of 
total bacterial 16S rRNA genes of epimural bacteria, and ruminal $\mathrm{pH}$, total VFA concentration, and expression of the TLR4 gene, suggested that the innate immune response in the epithelium is associated with the activity of the epimural bacteria. Currently, a total of 10 TLRs have been described in ruminants (Seabury et al., 2010) and two main groups may be distinguished: (i) TLRs1, 2, 4-6, 10, which are expressed in the cell surface and identify bacterial surface associated molecular patterns and (ii) TLRs3, 7-9 that recognize specific nucleic acids from viruses and bacteria (Chang, 2010; Guan et al., 2010; Malmuthuge et al., 2012). In spite of the knowledge available on the innate epithelial-associated response in adult ruminants, very few studies have addressed this in young animals. Malmuthuge et al. (2012) studied the regional and age-dependent expression patterns of TLRs, peptidoglycan recognition protein 1 (PGLYRP1), and antimicrobial proteins ( $\beta$-defensin) in the rumen, jejunum, ileum, cecum, and colon of 3 weeks and 6-month-old calves. The expression of most TLRs was significantly down regulated throughout the gastrointestinal tract with increasing age. The restricted expression of both $\beta$-defensin and PGLYRP1 prior to weaning in calves suggests that significant developmental changes occur in the epithelial immune system of cattle at this time. Malmuthuge et al. (2012) hypothesized that 'newborns may depend on TLRs as a primary innate immune mechanism to monitor commensal microflora and pathogens prior to weaning, but with increasing age it appears that other innate immune effecter mechanisms such as antimicrobial peptides may become more active in providing host defenses and minimizing harmful inflammatory responses'. No studies, however, have been conducted yet on to what extent the expression level of TLR respond to different microbial colonization patterns.

Recently, Liang et al. (2014) studied the potential regulatory role of micro RNAs (miRNAs) in the development of gastrointestinal tract (including the rumen), during the early life of dairy calves. The first finding is that the copy numbers of $16 \mathrm{~S}$ rRNA gene of Bifidobacterium or Lactobacillus species or both were positively correlated with miR-15/16, miR-29, and miR-196 expression levels $(P<0.05)$. The authors suggested miRNAs that were expressed differently could be regulators of the differentiation and proliferation of the cells of gastro-intestinal. Indeed Liang et al. (2014) identified three miRNAs as promoters of the gut-associated development at different levels: lymphoid tissues development (miR-196), dendritic cells maturation (miR-29), and of immune cells (miR-15/16). Their results provide novel evidence of gut development mechanisms that are regulated by host-microbiome interactions (Liang et al., 2014).

As stated earlier, the information of the impact of different colonization patterns on the immune system and the longterm effects is scarce. It could be hypothesized that if the colonization of a specific microbial group is prevented in early life, it is likely that the immune system will not recognize that group in later life if it colonizes the rumen later on. As a consequence, the host may mount an immune response against it. This might be a means to control specific populations. However, this is not entirely supported by the research conducted using protozoa-free raised lambs that were inoculated with protozoa later in life (Belanche et al., 2015). Nevertheless, more research is needed to understand the immune response in animals subjected to different microbial colonization patterns and how the animal responses later in life when it is challenged with the inoculation of 'unknown' species.

\section{CONCLUSION AND FUTURE PROSPECT}

The development of the rumen needs to be understood at different levels: anatomical, functional and microbial, as they have different temporal sequences in the young animal and the interplay of anatomical/functional rumen development and microbial development is not yet clear.

Notwithstanding the knowledge gaps, from the work described above, we conclude that early life events may be related to the microbial community structure and/or the rumen activity in the animals post-weaning. This would create differences in adaptive capacity due to different early life experiences and leading to the idea of microbial programming. However, the most effective window of time for intervention and the long-term implications are yet to be addressed. Therefore there is a need to perform trials that run long enough to truly assess the impact on the productive life of the animal. In addition, the differences in animal responses in later life need to be adequately assessed. In some cases, there will be no differences between animals reared differently in early life, which nevertheless have different microbiome compositions, if they are tested under 'standard' feeding conditions. The potential different response might become evident when the animals are nutritionally challenged or re-treated with the same pro- or anti-microbial compound as in early life.

Identifying the key immune elements at molecular level involved in early life colonization (with special attention to the rumen epimural population) may help to understand the hostanimal response and the extent of persistency of effects in adult life.

\section{ACKNOWLEDGMENTS}

This work is part of the FACCE-JPI project 'RumenStability' funded by INIA and DEFRA in Spain and UK, respectively. CN acknowledges the support of the Biotechnology and Biological Sciences Research Council, UK via grant number BB/J0013/1. DY-R acknowledges support from CSIC (Proyecto Intramural 201440E048) and from MINECO (grant BFU2014-57964-R). 


\section{REFERENCES}

Abecia, L., Martín-García, A. I., Martínez, G., Newbold, C. J., and Yáñez-Ruiz, D. R. (2013). Nutritional intervention in early life to manipulate rumen microbial colonization and methane output by kid goats postweaning. J. Anim. Sci. 91, 4832-4840. doi: 10.2527/jas.2012-6142

Abecia, L., Waddams, K. E., Martínez-Fernandez, G., Martín-García, A. I., RamosMorales, E., Newbold, C. J., et al. (2014a). An antimethanogenic nutritional intervention in early life of ruminants modifies ruminal colonization by Archaea. Archaea 2014, 841463. doi: 10.1155/2014/841463

Abecia, L., Ramos-Morales, E., Martínez-Fernandez, G., Arco, A., Martín-García, A. I., Newbold, C. J., et al. (2014b). Feeding management in early life influences microbial colonisation and fermentation in the rumen of newborn goat kids. Anim. Prod. Sci. 54, 1449-1454.

Anderson, K., Nagaraja, T., and Morrill, J. (1987). Ruminal metabolic development in calves weaned conventionally or early. J. Dairy Sci. 70, 1000-1005. doi: 10.3168/jds.S0022-0302(87)80105-4

Baldwin, R. L., and McLeod, K. R. (2000). Effects of diet forage:concentrate ratio and metabolizable energy intake on isolated rumen epithelial cell metabolism in vitro. J. Anim. Sci. 78, 771-783.

Baldwin, R. L., Vi McLeod, K. R., Klotz, J. L., and Heitmann, R. N. (2004). Rumen development, intestinal growth and hepatic metabolism in the preand postweaning ruminant. J. Dairy Sci. 87, E55-E65. doi: 10.3168/jds.S00220302(04)70061-2

Becker, E. R., and Hsiung, T. S. (1929). The method by which ruminants acquire their fauna of infusoria and remarks concerning experiments on host specificity of these protozoa. Proc. Natl. Acad. Sci. U.S.A. 15, 684-690. doi: 10.1073/pnas.15.8.684

Belanche, A., de la Fuente, G., and Newbold, C. J. (2014). Study of methanogen communities associated with different rumen protozoal populations. FEMS Microbiol. Ecol. 90, 663-677. doi: 10.1111/1574-6941.12423

Belanche, A., de la Fuente, G., and Newbold, C. J. (2015). Effect of progressive inoculation of fauna-free sheep with holotrich protozoa and total-fauna on rumen fermentation, microbial diversity and methane emissions. FEMS Microbiol. Ecol. 91, fiu026. doi: 10.1093/femsec/fiu026

Boyden, S. V. (1966). Cell-bound antibodies. Adv. Immunol. 5, 1-24. doi: 10.1016/S0065-2776(08)60271-0

Bryant, M. P., and Small, N. (1960). Observations on the ruminal microorganisms of isolate and inoculated calves. J. Dairy Sci. 43, 654-667. doi: 10.3168/jds.S0022-0302(60)90216-2

Castells, L., Bach, A., Aris, A., and Terré, M. (2013). Effects of forage provision to young calves on rumen fermentation and development of the gastrointestinal tract. J. Dairy Sci. 96, 5226-5236. doi: 10.3168/jds.2012-6419

Chang, Z. L. (2010). Important aspects of Toll-like receptors, ligands and their signaling pathways. Inflamm. Res. 59, 791-808. doi: 10.1007/s00011-010-0208-2

Chen, Y., Oba, M., and Guan, L. L. (2012). Variation of bacterial communities and expression of Toll-loke receptor genes in the rumen of steers differing in susceptibility to subacute ruminal acidosis. Vet. Microbiol. 59, 451-459. doi: 10.1016/j.vetmic.2012.04.032

Church, D. C. (1988). The Ruminant Animal: Digestive Physiology and Nutrition. Englewood Cliffs, NJ: Prentice-Hall, Inc.

Clemente, J. C., Ursell, L. K., Parfrey, L. W., and Knight, R. (2012). The impact of the gut microbiota on human health: an integrative view. Cell 148, 1258-1270. doi: 10.1016/j.cell.2012.01.035

Collado, M. C., Cernada, M., Baüerl, C., Vento, M., and Pérez-Martínez, G. (2012). Microbial ecology and host-microbiota interactions during early life stages. Gut Microbes 3, 352-365. doi: 10.4161/gmic.21215

Coverdale, J., Tyler, H., Quigley, J. D., and Brumm, J. A. (2004). Effect of various levels of forage and form of diet on rumen development and growth in calves. J. Dairy Sci. 87, 2554-2562. doi: 10.3168/jds.S0022-0302(04)73380-9

Davis, C. L., and Drackley, J. K. (1998). The Development, Nutrition, and Management of the Young Calf. Ames, IA: Iowa State University Press.

Dehority, B. A. (2003). Rumen Microbiology. Nottingham: Nottingham University Press.

De Paula Vieira, A., von Keyserlingk, M. A. G., and Weary, D. M. (2012). Presence of an older weaned companion influences feeding behaviour and improves performance of dairy calves before and after weaning from milk. J. Dairy Sci. 95, 3218-3224. doi: 10.3168/jds.2011-4821
Distel, R. A., Villalba, J. J., and Laborde, H. E. (1994). Effects of early experience on voluntary intake of low-quality roughage by sheep. J. Anim. Sci. 72, 1191-1195.

Dommett, R., Zilbauer, M., George, J. T., and Bajaj-Elliott, M. (2005). Innate immune defence in the human gastrointestinal tract. Mol. Immunol. 42, 903912. doi: 10.1016/j.molimm.2004.12.004

Eadie, J. M. (1962). The development of rumen microbial populations in lambs and calves under various conditions of management. J. Gen. Microbiol. 29, 563-578. doi: 10.1099/00221287-29-4-563

Eadie, J. M., Hobson, P. N., and Mann, S. O. (1959). A relationship between some bacteria, protozoa and diet in early weaned calves. Nature 183, 624-625. doi: 10.1038/183624a0

Faith, J. J., Guruge, J. L., Charbonneau, M., Subramanian, S., Seedorf, H., Goodman, A. L., et al. (2013). The long-term stability of the human gut microbiota. Science 341, 1237439. doi: $10.1126 /$ science. 1237439

Fall, C. H. (2011). Evidence for the intrauterine programming of adiposity for later life. Ann. Hum. Biol. 38, 410-428. doi: 10.3109/03014460.2011.592513

Faubladier, C., Julliand, V., Danel, J., and Philippeau, C. (2013). Bacterial carbohydrate-degrading capacity in foal faeces: changes from birth to preweaning and the impact of maternal supplementation with fermented feed products. Br. J. Nutr. 110, 1040-1052. doi: 10.1017/S0007114512006162

Fonty, G., Gouet, P., Jouany, J. P., and Senaud, J. (1987). Establishment of the microflora and anaerobic fungi in the rumen of lambs. J. Gen. Microbiol. 133, 1835-1843.

Fonty, G., Joblin, K., Chavarot, M., Roux, R., Naylor, G., and Michallom, F. (2007). Establishment and development of ruminal hydrogenotrophs in methanogenfree lambs. Appl. Environ. Microbiol. 73, 6391-6403. doi: 10.1128/AEM. 00181-07

Fouts, D. E., Szpakowski, S., Purushe, J., Torralba, M., Waterman, R. C., MacNeil, M. D., et al. (2012). Next generation sequencing to define prokaryotic and fungal diversity in the bovine rumen. PLOS ONE 7:e48289. doi: 10.1371/journal.pone.0048289

Gagen, E. J., Mosoni, P., Denman, S. E., Jassim, R. A., McSweeney, C. S., and Forano, E. (2012). Methanogen colonisation does not significantly alter acetogen diversity in lambs isolated $17 \mathrm{~h}$ after birth and raised aseptically. Microb. Ecol. 64, 628-640. doi: 10.1007/s00248-012-0024-z

Galef, B. G. Jr., and Giraldeau, L. A. (2001). Social influences on foraging in vertebrates: causal mechanisms and adaptive functions. Anim. Behav. 61, 3-15. doi: 10.1006/anbe.2000.1557

Goopy, J. P., Donaldson, A., Hegarty, R., Vercoe, P. E., Haynes, F., Barnett, M., et al. (2012). Low-methane yield sheep have smaller rumens and shorter rumen retention time. Br. J. Nutr. 11, 578-585. doi: 10.1017/S0007114513002936

Górka, P., Kowalski, Z. M., Pietrzak, P., Kotunia, A., Jagusiak, W., and Zabielski, R. (2011). Is rumen development in newborn calves affected by different liquid feeds and small intestine development? J. Dairy Sci. 94, 3002-3011. doi: 10.3168/jds.2010-3499

Greenwood, R. H., Morrill, J. L., Titgemeyer, E. C., and Kennedy, G. A. (1997). A new method of measuring diet abrasion and its effect on the development of the forestomach. J. Dairy Sci. 80, 2534-2541. doi: 10.3168/jds.S00220302(97)76207-6

Guan, Y., Ranoa, D. R., Jiang, S., Mutha, S. K., Li, X., Baudry, J., et al. (2010). Human TLRs 10 and 1 share common mechanisms of innate immune sensing but not signaling. J. Immunol. 184, 5094-5103. doi: 10.4049/jimmunol.0901888

Guzman, C. E., Bereza-Malcolm, L. T., De Groef, B., and Franks, A. E. (2015). Presence of selected methanogens, fibrolytic bacteria, and proteobacteria in the gastrointestinal tract of neonatal dairy calves from birth to 72 hours. PLoS ONE 10:e0133048. doi: 10.1371/journal.pone.0133048

Harrison, H. N., Warner, R. G., Sander, E. G., and Loosli, J. K. (1960). Changes in the tissue and volume of the stomachs of calves following the removal of dry feed or consumption of inert bulk. J. Dairy Sci. 43, 1301-1312. doi: 10.3168/jds.S0022-0302(60)90317-9

Hart, K. J., Yáñez-Ruiz, D. R., Duval, S. M., McEwan, N. R., and Newbold, C. J. (2008). Plant extracts to manipulate rumen fermentation. Anim. Feed Sci. Technol. 147, 8-35. doi: 10.1016/j.anifeedsci.2007.09.007

Heinrichs, J. (2005). Rumen development in the dairy calf. Adv. Dairy Technol. 17, 179-187.

Hooper, L. V., Littman, D. R., and Macpherson, A. J. (2012). Interactions between the microbiota and the immune system. Science 336, 1268-1273. doi: 10.1126/science. 1223490 
Jami, E., Israel, A., Kotser, A., and Mizrah, I. (2013). Exploring the bovine rumen bacterial community from birth to adulthood. ISME J. 7, 1069-1079. doi: 10.1038/ismej.2013.2

Jeyanathan, J., Martin, C., and Morgavi, D. P. (2014). The use of direct-fed microbials for mitigation of ruminant methane emissions: a review. Animal 8, 250-261. doi: 10.1017/S1751731113002085

Jiao, J., Li, X., Beauchemin, K. A., Tan, Z., Tang, S., and Zhou, C. (2015). Rumen development process in goats as affected by supplemental feeding v. grazing: age-related anatomic development, functional achievement and microbial colonisation. Br. J. Nutr. 113, 888-900. doi: 10.1017/S00071145140 04413

Khan, M. A., Lee, H. J., Lee, W. S., Kim, H. S., Kim, K. S., Hur, T. Y., et al. (2007). Structural growth, rumen development, and metabolic and immune responses of Holstein male calves fed milk through step-down and conventional methods. J. Dairy Sci. 90, 3376-3387. doi: 10.3168/jds.S0022-0302(07)71571-0

Khan, M. A., Lee, H. J., Lee, W. S., Kim, H. S., Kim, K. S., Park, S. B., et al. (2008). Starch source evaluation in calf starter: II. Ruminal parameters, rumen development, nutrient digestibilities, and nitrogen utilization in Holstein calves. J. Dairy Sci. 9, 1140-1149. doi: 10.3168/jds.2007-0337

Khan, M. A., Weary, D. M., and von Keyserlingk, M. A. (2011). Hay intake improves performance and rumen development of calves fed higher quantities of milk. J. Dairy Sci. 94, 3547-3553. doi: 10.3168/jds.2010-3871

Kittelmann, S., Pinares-Patiño, C. S., Seedorf, H., Kirk, M. R., Ganesh, S., McEwan, J. C., et al. (2014). Two different bacterial community types are linked with the low-methane emission trait in sheep. PLOS ONE 9:e103171. doi: 10.1371/journal.pone.0103171

Klieve, A. V., Hennessy, D., Ouwerkerk, D., Forster, R. J., Mackie, R. I., and Attwood, G. T. (2003). Establishing populations of Megasphaera elsdenii YE 34 and Butyrivibrio fibrisolvens YE 44 in the rumen of cattle fed high grain diets. J. Appl. Microbiol. 95, 621-630. doi: 10.1046/j.1365-2672.2003.02024.x

Kristensen, N. B., Sehested, J., Jensen, S. K., and Vestergaard, M. (2007). Effect of milk allowance on concentrate intake, ruminal environment, and ruminal development in milk-fed Holstein calves. J. Dairy Sci. 90, 4346-4355. doi: 10.3168/jds.2006-885

Kuhn, K. A., and Stappenbeck, T. S. (2012). Peripheral education of the immune system by the colonic microbiota. Semin. Immunol. 25, 364-369. doi: 10.1016/j.smim.2013.10.002

Landy, M., and Weidanz, W. P. (1964). "Natural antibodies against gram negative bacteria," in Bacterial Endotoxins, eds M. Landy and W. Braun (New Brusnwick, NJ: Rutgers University Press).

Lane, M., Baldwin, R., and Jesse, B. (2002). Developmental changes in ketogenic enzyme gene expression during sheep rumen development. J. Anim. Sci. 80, 1538-1544.

Latham, M. J., Sharpe, M. E., and Suton, J. D. (1971). The microbial flora of the rumen of cows fed hay and high cereal rations and its relationship to the rumen fermentation. J. Appl. Bacteriol. 34, 425-434. doi: 10.1111/j.13652672.1971.tb02302.x

Lesmeister, K. E., and Heinrichs, A. J. (2004). Effects of corn processing on growth characteristics, rumen development, and rumen parameters in neonatal dairy calves. J. Dairy Sci. 87, 3439-3450. doi: 10.3168/jds.S0022-0302(04)73340-8

Lesmeister, K. E., and Heinrichs, A. J. (2005). Effects of adding extra molasses to a texturized calf starter on rumen development, growth characteristics, and blood parameters in neonatal dairy calves. J. Dairy Sci. 88, 411-418. doi: 10.3168/jds.S0022-0302(05)72702-8

Lesmeister, K. E., Heinrichs, A. J., and Gabler, M. T. (2004). Effects of supplemental yeast (Saccharomyces cerevisiae) culture on rumen development, growth characteristics, and blood parameters in neonatal dairy calves. J. Dairy Sci. 87, 1832-1839. doi: 10.3168/jds.S0022-0302(04)73340-8

Li, R. W., Connor, E. E., Li, C., Baldwin Vi, R. L., and Sparks, M. E. (2012). Characterization of the rumen microbiota of pre-ruminant calves using metagenomic tools. Environ. Microbiol. 14, 129-139. doi: 10.1111/j.14622920.2011.02543.x

Liang, G., Malmuthuge, N., McFadden, T. B., Bao, H., Griebel, P. J., Stothard, P., et al. (2014). Potential regulatory role of microRNAs in the development of bovine gastrointestinal tract during early life. PLoS ONE 9:92592. doi: 10.1371/journal.pone.0092592

Malmuthuge, N., Griebel, P. J., and Guan, L. L. (2014). Taxonomic identification of commensal bacteria associated with the mucosa and digesta throughout the gastrointestinal tracts of preweaned calves. Appl. Environ. Microbiol. 80, 2021-2028. doi: 10.1128/AEM.03864-13

Malmuthuge, N., Li, M., Fries, P., Griebel, P. J., and Guan, L. L. (2012). Regional and age dependent changes in gene expression of Toll-like receptors and key antimicrobial defence molecules throughout the gastrointestinal tract of dairy calves. Vet. Immunol. Immunopathol. 146, 18-26. doi: 10.1016/j.vetimm.2012.01.010

Martin, S. A., and Nisbet, D. J. (1992). Effect of direct-fed microbials on rumen microbial fermentation. J. Dairy Sci. 75, 1736-1744. doi: 10.3168/jds.S00220302(92)77932-6

McCann, J. C., Wickersham, T. A., and Loor, J. (2014). High-throughput methods redefine the rumen microbiome and its relationship with nutrition and metabolism. Bioinform. Biol. Insights 8, 109-125. doi: 10.4137/BBI. S15389

Meade, K. G., Cormican, P., Narciandi, F., Lloyd, A., and O’Farrelly, C. (2014). Bovine -defensin gene family: opportunities to improve animal health? Physiol. Genomics 46, 17-28. doi: 10.1152/physiolgenomics.00085.2013

Morvan, B., Doré, J., Rieu-Lesme, F., Foucat, L., Fonty, G., and Gouet, P. (1994). Establishment of hydrogen-utilizing bacteria in the rumen of the newborn lamb. FEMS Microbiol. Lett. 117, 249-256. doi: 10.1111/j.15746968.1994.tb06775.x

Mueller, R. E., Asplund, J. M., and Iannotti, E. L. (1984a). Successive changes in the epimural bacterial community of young lambs as revealed by scanning electron microscopy. Appl. Environ. Microbiol. 47, 715-723.

Mueller, R. E., Iannotti, E. L., and Asplund, J. M. (1984b). Isolation and identification of adherent epimural bacteria during succession in young lambs. Appl. Environ. Microbiol. 47, 724-730.

Nakanishi, Y., Arave, C. W., and Stewart, P. H. (1993). Effects of feeding Lactobacillus acidophilus yogurt on performance and behavior of dairy calves. J. Dairy Sci. 76, 244-254.

Nocek, J. E., Heald, C. W., and Polan, C. E. (1984). Influence of ration physical form and nitrogen availability on ruminal morphology of growing bull calves. J. Dairy Sci. 67, 334-343. doi: 10.3168/jds.S0022-0302(84)81403-4

Orpin, J. C., and Joblin, K. N. (1988). "The rumen anaerobic fungi," in The Rumen Microbial Ecosystem, ed. P. N. Hobson (London: Elssevier Applied Sciebce), $140-195$.

Owens, F. N., Dubeski, P., and Hanson, C. (1993). Factors that alter the growth and development of ruminants. J. Anim. Sci. 71, 3138-3150.

Palmonari, A., Stevenson, D. M., Mertens, D. R., Cruywagen, C. W., and Weimer, P. J. (2010). pH dynamics and bacterial community composition in the rumen of lactating dairy cows. J. Dairy Sci. 93, 279-287. doi: 10.3168/jds.2009-2207

Petri, R. M., Schwaiger, T., Penner, G. B., Beauchemin, K. A., Forster, R. J., McKinnon, J. J., et al. (2013). Characterization of the core rumen microbiome in cattle during transition from forage to concentrate as well as during and after an acidotic challenge. PLOS ONE 8:e83424. doi: 10.1371/journal.pone.0083424

Phillips, C. J. (2004). The effects of forage provision and group size on the behavior of calves. J. Dairy Sci. 87, 1380-1388. doi: 10.3168/jds.S0022-0302(04)73287-7

Provenza, F. D., and Balph, D. F. (1990). "Applicability of five diet selection models to various foraging challenges ruminants encounter," in Behavioural Mechanisms of Food Selection, ed. R. N. Hughes (Berlin: Springer-Verlag), 423-459.

Rey, M., Enjalbert, F., Combes, S., Cauquil, L., Bouchez, O., and Monteil, V. (2013). Establishment of ruminal bacterial community in dairy calves from birth to weaning is sequential. J. Appl. Microbiol. 116, 245-257. doi: 10.1111/jam. 12405

Rey, M., Enjalbert, F., and Monteils, V. (2012). Establishment of ruminal enzyme activities and fermentation capacity in dairy calves from birth through weaning. J. Dairy Sci. 95, 1500-1512. doi: 10.3168/jds.2011-4902

Reynolds, C., Dürst, B., Lupoli, B., Humphries, D. J., and Beever, D. E. (2004). Visceral tissue mass and rumen volume in dairy cows during the transition from late gestation to early lactation. J. Dairy Sci. 87, 961-971. doi: 10.3168/jds.S00220302(04)73240-3

Rieu, F., Fonty, G., Gaillard, B., and Gouet, P. (1990). Electron microscopy study of the bacteria adherent to the rumen wall in young conventional lambs. Can. J. Microbiol. 36, 140-144. doi: 10.1139/m90-025

Sadet, S., Martin, C., Meunier, B., and Morgavi, D. P. (2007). PCR-DGGE analysis reveals a distinct diversity in the bacterial population attached to the rumen epithelium. Animal 1, 939-944. doi: 10.1017/S175173110700 0304 
Seabury, C. M., Seabury, P. M., Decker, J. E., Schnabel, R. D., Taylor, J. F., and Womack, J. E. (2010). Diversity and evolution of 11 innate immune genes in Bos taurus taurus and Bos taurus indicus cattle. Proc. Natl. Acad. Sci. U.S.A. 107, 151-156. doi: 10.1073/pnas.0913006107

Sharpe, M. E., Latham, M. J., and Reiter, B. (1969). The microbial flora of the rumen of cows fed hay and high cereal rations and its relationship to the rumen fermentation. J. Gen. Microbiol. 56, 353-364. doi: 10.1099/00221287-56-3-353

Sharpe, M. E., Latham, M. J., and Reiter, B. (1977). "The immune response of the hosts animal to bacteria in the rumen and caecum," in Proceedings of the IV International Symposium on Ruminant Physiology: Digestion and Metabolism in the Ruminant, Sydney, Australia, August 1974, ed. A. C. I. Ian Wilbur McDonald (Armidale, NSW: University of New England Publishing Unit).

Silper, B. F., Lana, A. M., Carvalho, A. U., Ferreira, C. S., Franzoni, A. P., Lima, J. A., et al. (2014). Effects of milk replacer feeding strategies on performance, ruminal development, and metabolism of dairy calves. J. Dairy Sci. 97, 1016-1025. doi: 10.3168/jds.2013-7201

Skillman, L. C., Evans, P. N., Naylor, G. E., Morvan, B., Jarvis, G. N., and Joblin, K. N. (2004). 16S ribosomal DNA-directed PCR primers for ruminal methanogens and identification of methanogens colonising young lambs. Anaerobe 10, 277-285. doi: 10.1016/j.anaerobe.2004.05.003

Snoeck, V., Peters, I. R., and Cox, E. (2006). The IgA system: a comparison of structure and function in different species. Vet. Res. 37, 455-467. doi: 10.1051/vetres:2006010

Soberon, F., Raffrenato, E., Everett, R. W., and Van Amburgh, M. E. (2012). Preweaning milk replacer intake and effects on long-term productivity of dairy calves. J. Dairy Sci. 95, 783-793. doi: 10.3168/jds.2011-4391

Stewart, C. S., Fonty, G., and Gouet, P. (1988). The establishment of rumen microbial communities. Anim. Feed Sci. Technol. 21, 69-97. doi: 10.1016/03778401(88)90093-4

Strelkov, A., Polijansky, G., and Issakowa-Keo, M. (1933). Uber die infektionswege der im pansen und in der haube der Wiederkauer befindlichen insorien. Arch. Tierernahr. Tierz. 9, 679-697.

Suárez, B. J., Van Reenen, C. G., Gerrits, W. J., Stockhofe, N., van Vuuren, A. M., and Dijkstra, J. (2006). Effects of supplementing concentrates differing in carbohydrate composition in veal calf diets: II. Rumen development. J. Dairy Sci. 89, 4376-4386. doi: 10.3168/jds.S0022-0302(06)72483-3

Suárez, B. J., Van Reenen, C. G., Stockhofe, N., Dijkstra, J., and Gerrits, W. J. (2007). Effect of roughage source and roughage to concentrate ratio on animal performance and rumen development in veal calves. J. Dairy Sci. 90, 2390-2403. doi: $10.3168 /$ jds.2006-524

Subharat, S., Shu, D., Zheng, T., Buddle, B. M., Janssen, P. H., Luo, D., et al. (2015). Vaccination of cattle with a methanogen protein produces specific antibodies in the saliva which are stable in the rumen. Vet. Immunol. Immunopathol. 164, 201-207. doi: 10.1016/j.vetimm.2015.02.008

Tamate, H., McGilliard, A. D., Jacobson, N. L., and Getty, R. (1962). Effect of various dietaries on the anatomical development of the stomach in the calf. J. Dairy Sci. 45, 408-420. doi: 10.3168/jds.S0022-0302(62)89406-5

Theodorou, M. K., Beever, D. E., Haines, M. J., and Brooks, A. (1990). The effect of a fungal probiotic on intake and performance in early weaned lambs. Anim. Prod. 53, 577.

Trevisi, E., Amadori, M., Riva, F., Bertoni, G., and Bani, P. (2014). Evaluation of innate immune responses in bovine forestomachs. Res. Vet. Sci. 96, 69-78. doi: 10.1016/j.rvsc.2013.11.011

Wardrop, I., and Coombe, J. (1960). The post-natal growth of the visceral organs of the lamb I. The growth of the visceral organs of the grazing lamb from birth to sixteen weeks of age. J. Agric. Sci. 54, 140-143.
Warner, R. G., Flatt, W. P., and Loosli, J. K. (1956). Dietary factors influencing the development of the ruminant stomach. J. Agric. Food Chem. 4, 788-792. doi: $10.1021 /$ jf60067a003

Weimer, P. J., Stevenson, D. M., Mantovani, H. C., and Man, S. L. (2010). Host specificity of the ruminal bacterial community in the dairy cow following near-total exchange of ruminal contents. J. Dairy Sci. 93, 5902-5912. doi: $10.3168 /$ jds.2010-3500

Williams, A. G., and Coleman, G. S. (1992). The Rumen Protozoa. New York, NY: Springer-Verlag.

Williams, Y. J., Popovski, S., Rea, S. M., Skillman, L. C., Toovey, A. F., Northwood, K. S., et al. (2009). A vaccine against rumen methanogens can alter the composition of archaeal populations. Appl. Environ. Microbiol. 75, 1860-1866. doi: 10.1128/AEM.02453-08

Wu, G., Bazer, F. W., Wallace, J. M., and Spencer, T. M. (2006). Intrauterine growth retardation: implications for the animal sciences. J. Anim. Sci. 84, 2316-2337. doi: $10.2527 /$ jas.2006-156

$\mathrm{Wu}, \mathrm{H} .-\mathrm{J}$. , and $\mathrm{Wu}, \mathrm{E} .(2012)$. The role of gut microbiota in immune homeostasis and autoimmunity. Gut Microbes 3, 4-14. doi: 10.4161/gmic. 19320

Yáñez-Ruiz, D. R., Macías, B., Pinloche, E., and Newbold, C. J. (2010). The persistence of bacterial and methanogenic archaeal communities residing in the rumen of young lambs. FEMS Microbiol. Ecol. 72, 272-278. doi: 10.1111/j.15746941.2010.00852.x

Yáñez-Ruiz, D. R., Williams, S., and Newbold, C. J. (2007). The effect of absence of protozoa on rumen biohydrogenation and the fatty acid composition of lamb muscle. Br. J. Nutr. 97, 938-948. doi: 10.1017/S0007114507675187

Zhong, R. Z., Sun, H. X., Li, G. D., Liu, H. W., and Zho, D. W. (2014). Effects of inoculation with rumen fluid on nutrient digestibility, growth performance and rumen fermentation of early weaned lambs. Livest. Sci. 162, 154-158. doi: 10.1016/j.livsci.2013.12.021

Ziolecka, A., Osinska, Z., and Ziolecki, A. (1984a). The effect of stabilized rumen extract on growth and development of calves. 1. Liveweight gain and efficiency of feed utilization. Z. Tierphysiol. Tierrernahr. Futtermittelkd. 51, 13-20. doi: 10.1111/j.1439-0396.1984.tb01406.x

Ziolecka, A., Kwiatkowska, E., and Laskowska, H. (1984b). The effect of stabilized rumen extract on growth and development of calves. 2 . Digestive activity in the rumen and development of microflora in the rumen and faeces. Z. Tierphysiol. Tierrernahr. Futtermittelkd. 51, 20-31. doi: 10.1111/j.1439-0396.1984. tb01407.x

Ziolecki, A., and Briggs, C. A. (1961). The microflora of the rumen of young calf: II. Source, nature and development. J. Appl. Bacteriol. 24, 148-163. doi: 10.1111/j.1365-2672.1961.tb00247.x

Zitnan, R., Voigt, J., Schonhusen, U., Wegner, J., Kokardova, M., Hagemeister, H., et al. (1998). Influence of dietary concentrate to forage ratio on the development of rumen mucosa in calves. Arch. Anim. Nutr. 51, 279-291.

Conflict of Interest Statement: The authors declare that the research was conducted in the absence of any commercial or financial relationships that could be construed as a potential conflict of interest.

Copyright (c) 2015 Yáñez-Ruiz, Abecia and Newbold. This is an open-access article distributed under the terms of the Creative Commons Attribution License (CC BY). The use, distribution or reproduction in other forums is permitted, provided the original author(s) or licensor are credited and that the original publication in this journal is cited, in accordance with accepted academic practice. No use, distribution or reproduction is permitted which does not comply with these terms. 